\title{
Effect of Furnish on Temperature and Vapor Pressure Behavior in the Center of Mat Panels during Hot Pressing
}

\author{
Muhammad Navis Rofii ${ }^{1,2,3}$, Noriko Yamamoto $^{1}$, Yoichi Kojima ${ }^{1} \&$ \\ Shigehiko Suzuki ${ }^{1}$ \\ ${ }^{1}$ Faculty of Agriculture Shizuoka University, 836 Ohya, Shizuoka 422-8529, Japan \\ ${ }^{2}$ United Graduate School of Agricultural Science Gifu University, Gifu 501-1193, Japan \\ ${ }^{3}$ Faculty of Forestry Universitas Gadjah Mada, Jalan Agro 1, Bulaksumur, \\ Yogyakarta 55281, Indonesia \\ Email: navis_r@ugm.ac.id
}

\begin{abstract}
Particleboard achieves its overall performance characteristics during hot pressing process. As this process is influenced by several factors, particularly temperature and pressure, it is very important to understand the behavior of both. This study investigates the effects of furnish materials on temperature and vapor pressure behavior inside particleboard mat panels during hot pressing. Strand type particles from hinoki and ring-flaker recycled wood particles were used as furnish for laboratory-scale particleboard panels with a target density of 0.76 $\mathrm{g} / \mathrm{cm}^{3}$. Mat panels with a moisture content of about $10 \%$ were hot pressed at a platen temperature of $180^{\circ} \mathrm{C}$ and an initial pressure of $3 \mathrm{MPa}$ until the mat center reached the same temperature as the platen. A press monitoring device (PressMAN Lite) was used for detecting the temperature and vapor pressure change in the center of the mat panels. The study showed that the furnish type affected the temperature and vapor behavior inside the mat panels. Particleboard made of hinoki strand resulted in a longer plateau time, a higher plateau temperature and a higher gas pressure generated during hot pressing than those of ring-flaker recycled wood particles. Mixed board resulted in values between those of the two other furnish materials.
\end{abstract}

Keywords: furnish type; mat panels; hot pressing; temperature; vapor pressure

\section{$1 \quad$ Introduction}

Hot pressing plays a very important role during particleboard production in determining overall particleboard performance. The hot-press provides the thermal energy and mechanical compression force to consolidate the mat [1]. This complex process includes heat and mass transfer inside the mat of the panels [2]. Essentially, temperature and gas pressure affect the hot pressing process and the properties of the wood-based panels [3]. Due to the compaction of air inside the mat as well as the vaporization of the water and volatile compounds from the wood particles and the adhesive, an internal gas pressure develops inside the mat during hot pressing. The level of gas pressure inside the mat affects heat convection into the mat. On the other hand, the gas pressure

Received September $24^{\text {th }}, 2013$, Revised November $1^{\text {st }}, 2013$, Accepted for publication May $12^{\text {th }}, 2014$.

Copyright (C) 2014 Published by ITB Journal Publisher, ISSN: 2337-5760, DOI: 10.5614/j.math.fund.sci.2014.46.2.6 
level also affects the internal temperature [4]. Therefore, the interaction between both is important for understanding the process inside the mat panels during hot pressing.

The furnish material related to its source, such as wood species and particle type, is a well known factor that influences particleboard performance. In their study, Maku, et al. [5] found that particle geometry affects the vapor flow in the mat panels and subsequently temperature rise. The structure of the mat panels is one factor for understanding the heat and mass transfer inside the mat panels. It is related to the porous structure through which the water vapor flows, which influences the rate of the vertical and horizontal mass transfer $[1,6]$. They also state that a substantial change in mat structure, such as its physical properties, will affect the rate of heat and mass transfer.

The period of constant temperature occurring in the centerline of the mat, i.e. the plateau time, and the constant temperature, i.e. the plateau temperature, were used as indicators for determining temperature behavior inside the mat panels. A plateau was found in the temperature-increase curve where it remains almost constant because of the latent heat of vaporization and the vapor pressuremoisture content-temperature equilibrium [1]. The vapor pressure generated during the hot pressing was also determined. The purpose of this study was to determine the effects of different furnish types on the temperature and vapor pressure behavior inside the particleboard mat during hot pressing.

\section{$2 \quad$ Materials and Methods}

Hinoki strand (HS) and ring-flaker recycled wood particles (RW), obtained from the wood industry, were used as furnish for laboratory-scale particleboard production. Recycled wood particles were obtained by a ring-flaker process of waste wood demolition. All furnish was conditioned to approximately 5\% moisture content before blending. Figure 1 shows the two different raw materials used in this study. Urea formaldehyde (UF) resin with $65.5 \%$ solid content was used as adhesive. The resin was applied to the furnish at $9 \%$ based on oven-dry weight in a rotating blending box fitted with a pneumatic spray gun. The mat moisture content before pressing was controlled at around $10 \%$.

Particle mats were created manually without orientation. The dimensions of the particleboards were $320 \times 340 \times 10 \mathrm{~mm}$ and the target density of the pressed board was $0.76 \mathrm{~g} / \mathrm{cm}^{3}$. The mats were hot-pressed with a platen temperature of $180^{\circ} \mathrm{C}$ and an initial pressure of $3 \mathrm{MPa}$ until the mat center reached a temperature of $180^{\circ} \mathrm{C}$. The temperature and vapor pressure changes inside the mat panels were monitored using a PressMAN Lite (Alberta Research Council, 
Canada) that was inserted into the center of the mat panel (Figure 2). The behaviors of temperature and vapor pressure were characterized in a curve.

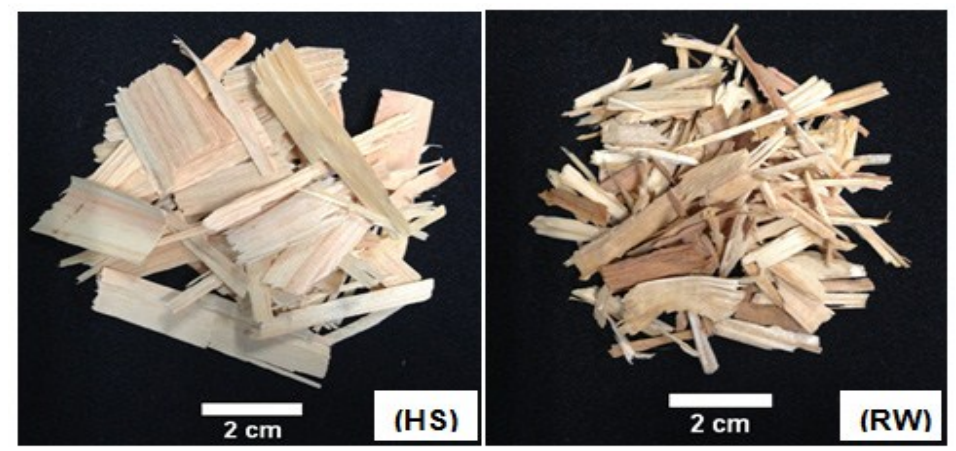

Figure 1 Furnish types used in the study.
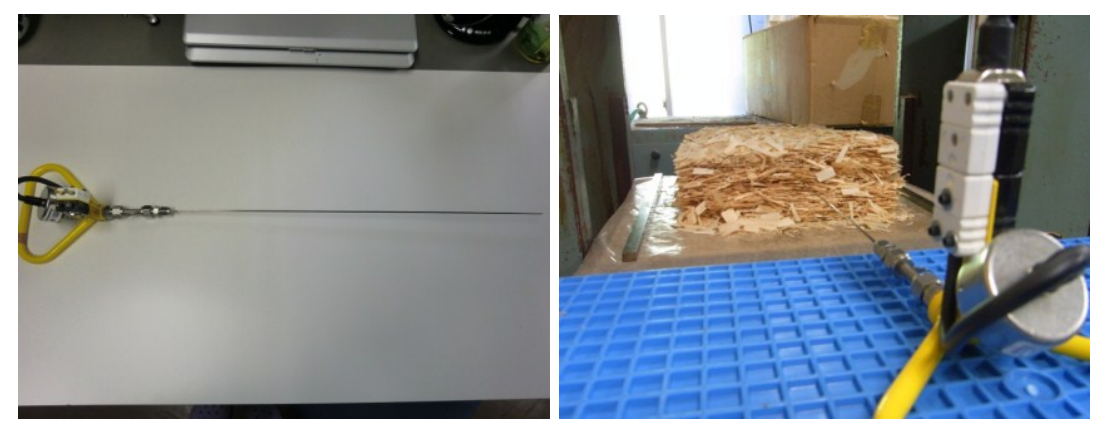

Figure 2 PressMAN Lite sensor device and its application.

\section{$3 \quad$ Results and Discussion}

\subsection{Temperature Behavior}

The temperature behavior at the centre of the mat panels is characterized as a curve in Figure 3. The curve can be divided into three stages [7,8]. The first stage is the stage of rapidly rising temperature to reach the boiling point of water at $100^{\circ} \mathrm{C}$. In this stage, the heat is transferred from the platen to the core layer by conduction and convection. Convection occurs when the heat transfer causes vaporization of the furnish's moisture [9]. The second stage is the stage of vaporization, when the moisture changes to vapor while the core temperature does not change, pronounced by a temperature plateau during a period called plateau time. In the second stage, heat is transferred by convection. The third stage is the stage during which the vaporization process ends and the 
temperature gradually increases again. The heat in this stage is transferred by conduction.

The different raw material sources used in this study affected the temperature behavior inside the mat panels. As shown in Figure 3, the recycled wood particles resulted in a shorter period for the core temperature to reach $100^{\circ} \mathrm{C}$ than the hinoki strand. This is due to the fact that recycled wood particles are more permeable than those of hinoki strand; the heat transfer by convection caused the mat panels made of recycled wood to reach the temperature of boiling water faster than that those made of hinoki strand. Humphrey and Bolton [9] note that any change in temperature will affect the equilibrium moisture content in wood, thus the partial pressure of the vapor in the surrounding air. The vapor pressure generated in this condition causes heat transfer by convection. As reported by Garcia, et al. [10], a highly permeable mat allows a rapid initial vapor flow to quickly heat the core by efficient convection heat transfer.

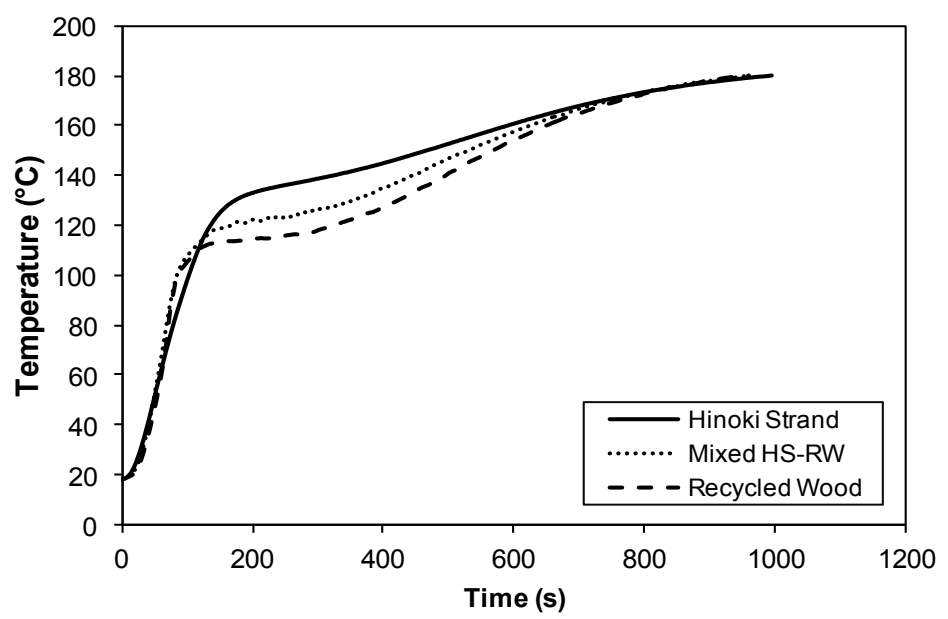

Figure 3 Temperature change curve inside the mat panels for different furnish types.

During the vaporization stage, when the temperature plateau occurred, we found different phenomena of temperature behavior between both types of furnish materials. The mat panels from recycled wood yielded a shorter plateau time (Figure 4). The recycled wood particles were produced using a ring-flaker process of waste wood demolition. Because these particles are shorter and thicker than those of hinoki strand, it causes a more porous structure of the mat. A porous structure is related to the permeability of water vapor. Since the rate of mass transfer process is dominated by the flow of water vapor through the 
porous structure [6], it results in a shorter plateau time period for mat panels from recycled wood than for mats from hinoki strand.

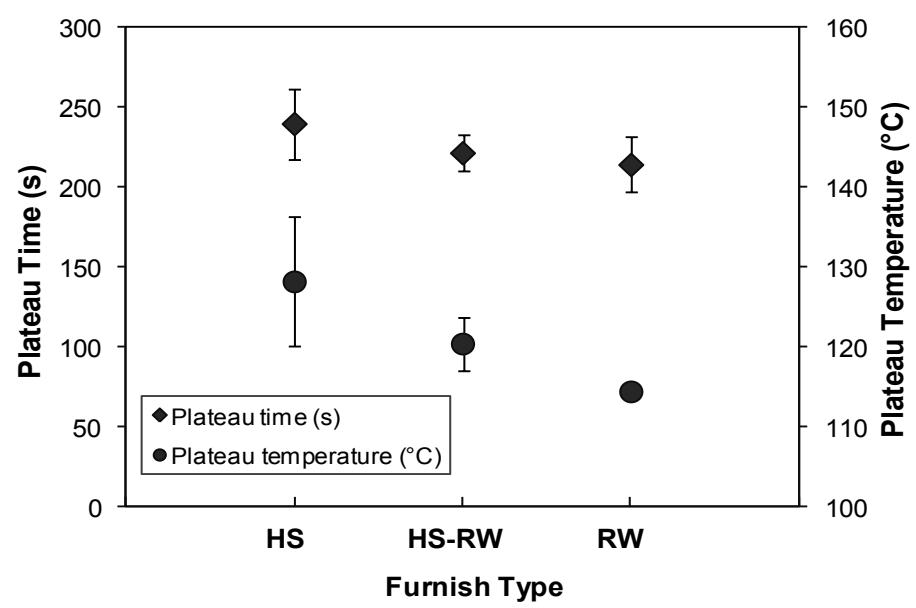

Figure 4 Average plateau time and temperature of the mat center during hot pressing.

We also found a big difference between the two furnish types in the plateau temperature, where the hinoki strand resulted in a higher plateau temperature than that of recycled wood, with a difference of about $20^{\circ} \mathrm{C}$. One reason can be explained that recycled wood particles yield a mat panel with a high permeability. The flow of water vapor will be released easily through the porous structure which causes latent heat in the centre of mat to become lower and consequently, it results in a lower core temperature. On the other hand, hinoki strand yields a mat panel with a low permeability. This contributes to a slower core temperature increase, a higher maximum core temperature and a longer plateau time, as can be seen in Figures 3 and 4.

\subsection{Vapor Pressure Behavior}

Figure 5 provides the vapor pressure behavior in the mat centre of the hinoki strand board. Taken together, Figures 3 and 5 show that the vapor pressure starts to increase after the core temperature reaches approximately $80^{\circ} \mathrm{C}$, or, before the boiling point of water $\left(100^{\circ} \mathrm{C}\right)$. The rapid rise of the vapor pressure occurs up to the moment the temperature change becomes constant and the vaporization stage starts. During this period, called plateau time, the heat vaporizes the moisture and generates the highest vapor pressure. This implies that the plateau time period is apparently identical to the vaporization stage and, referring to Figure 4, a longer plateau time means a longer vaporization stage. At the end of the vaporization stage, the vapor pressure decreases rapidly and 
the temperature starts to increase slowly. This indicates that the mat panels have almost reached their final thickness because of mat consolidation and therefore the heat is transferred only by conduction.

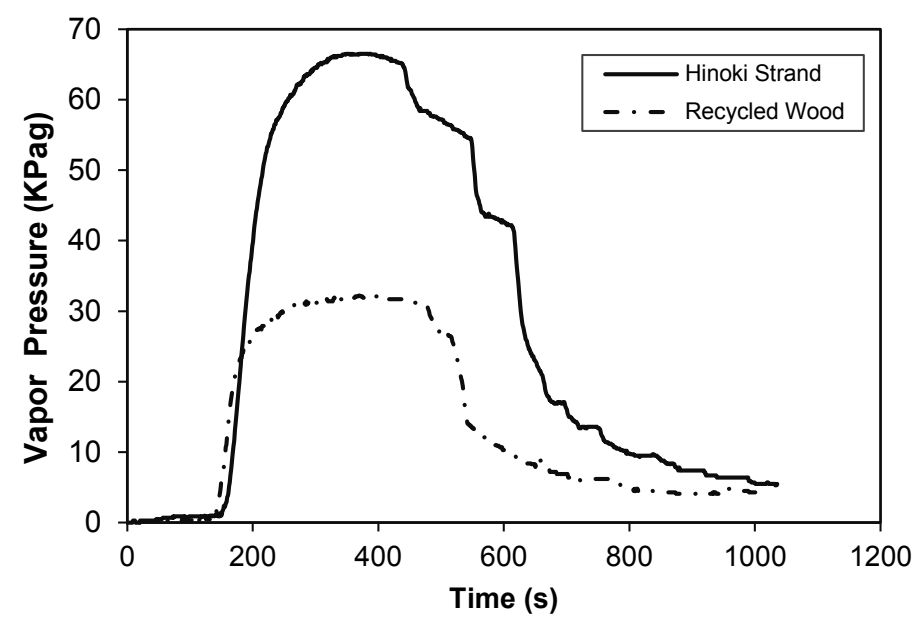

Figure 5 Representative vapor pressure curve at the center of the mat panels.

It was also found that the vapor pressure generated inside the mat panels was affected by the different furnish materials. This study shows that the rise of vapor pressure in the recycled wood particle boards begins sooner than in the other furnish type boards. This is related to the time it takes to reach a core temperature of $100^{\circ} \mathrm{C}$, where the recycled wood reaches this temperature faster than the other furnish types (see Figure 3). Because the recycled wood furnish is more permeable, the vapor is easier to move and transfers the heat by convection in the first stage of temperature rise. The highest vapor pressure was generated by the hinoki strand mat panels, followed by the mixed panels, while the lowest was that of recycled wood particle boards. The vapor pressures generated by hinoki strand and mixed board were about twice as high. The difference in vapor pressure may be due to the permeability of the mat panels. The hinoki particles are less permeable and therefore the vapor pressure inside the mat is harder to move and leads to a higher pressure. Wide and thin particles such as hinoki strand are able to align themselves in a planer orientation, thus creating strong resistance to gas flow, while thick particles promote gaps at their edges where particles overlap. Particles with a large aspect ratio are able to bridge gaps and contribute to compression resistance as a result of bending [1]. The vaporization stage of hinoki strand mat lasts longer than that of ring-flaked recycled wood particles. This implies that less permeable mat panels need a much longer time in the vaporization stage, which consequently results in a longer pressing time. 


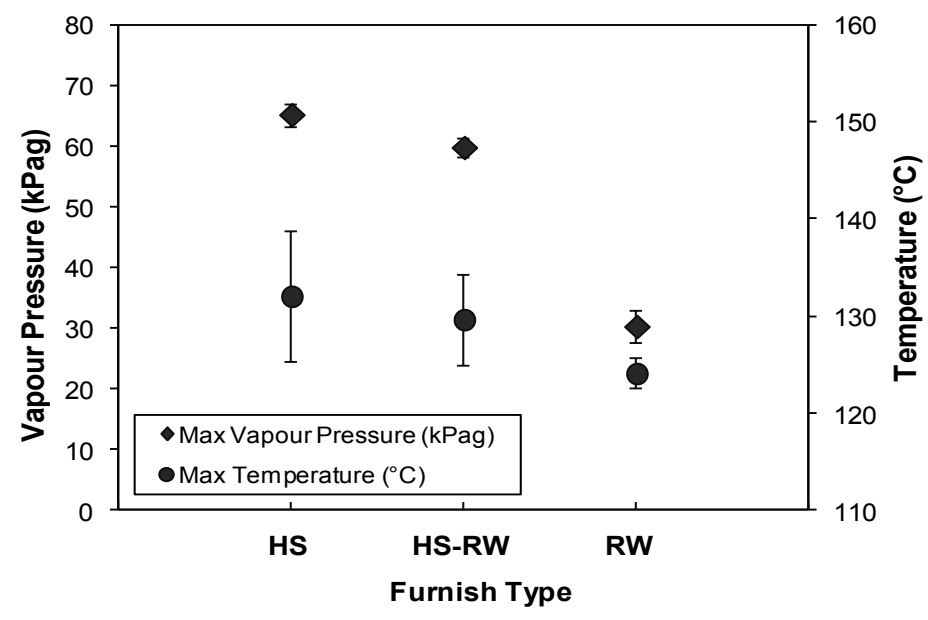

Figure 6 Maximum vapor pressure and temperature during vaporization stage.

Figure 6 shows the values of maximum vapor pressure and maximum temperature at the centre of the mat panels from different furnish types during the vaporization stage. The maximum vapor pressure was higher for hinoki strand than recycled wood. This might be due to the condition that hinoki strand is more compact during pressing so the vapor pressure can be higher. The more porous structure of the recycled wood mat causes the vapor to move easily to the edge of the mat panels and generated a lower vapor pressure. The maximum core temperature is strongly affected by the vapor pressure and therefore hinoki strand produced the highest maximum core temperature, followed by the mixedmat panel and recycled wood, respectively. This find is similar to the study of Garcia, et al. [10], who states that a cooler temperature during the vaporization stage can be attributed to low gas pressure.

\section{Conclusions}

In this study, temperature and vapor pressure behaviors inside mat panels during hot pressing were investigated in relation to furnish type. It was found that furnish type affected temperature and vapor pressure changes. The flatter, longer and thinner raw material of hinoki strand resulted in a longer plateau time, a higher plateau temperature, a higher vapor pressure, and a higher maximum core temperature during hot pressing than those of ring-flaker recycled wood particles. The mixed mat panels resulted in different temperature and vapor pressure behavior characteristics than those of the other two furnish types. This study also showed that both the temperature and vapor pressure strongly influence each other. 


\section{Acknowledgements}

M.N. Rofii thanks to the Directorate General of Higher Education, Republic of Indonesia, for its financial support during his doctoral course program through DIKTI Scholarship.

\section{References}

[1] Kamke, F.A., Physic of Hot Pressing, in Proceedings of Fundamentals of Composite Processing, General Technical Report FPL-149, USDA Forest Service, Forest Products Laboratory, Madison, Wisconsin, pp. 3-18, 2004.

[2] Kavazovic, Z., Deteix, J., Cloutier, A. \& Fortin, A., Sensitivity Study of a Numerical Model of Heat and Mass Transfer Involved during the Medium-density Fibreboard Hot Pressing Process, Wood and Fiber Science, 42(2), pp. 130-149, 2010.

[3] Steffen, A.V., Haas, G., Rapp, A., Humphrey, P.E. \& Thoemen, H., Temperature and Gas Pressure in MDF-mats during Industrial Continuous Hot Pressing, Holz als Roh- und Werkstoff, 57, pp. 154-155, 1999.

[4] Meyer, N. \& Thoemen, H., Gas Pressure Measurements during Continuous Hot Pressing of Particleboard, Holz als Roh- und Werkstoff, 65, pp. 49-55, doi: 10.1007/s00107-006-0140-x, 2007.

[5] Maku, T., Hamada, R. \& Sasaki, H., Studies on the Particleboard, Report 4: Temperature and Moisture Distribution in Particleboard during Hotpressing, Wood Research Kyoto University, 21, pp. 34-46, 1959.

[6] Zombori, B.G., Kamke, F.A. \& Watson, L.T., Simulation of the Internal Conditions during the Hot-Pressing Process, Wood and Fiber Science, 35(1), pp. 2-23, 2003.

[7] Wu, J., Yu, Z. \& Chen, T., Heat-transfer Process during Hot-Pressing of Flakeboard, Frontiers of Forestry in China, 3, pp. 343-347, 2006. (doi: 10.1007/s11461-006-0007-7)

[8] Rofii, M.N., Yamamoto, N., Ueda, S., Kojima, Y. \& Suzuki, S., The Temperature Behavior Inside the Mat of Wood-based Panel during Hot pressing under Various Manufacturing Conditions, Journal of Wood Science, 60, 2014. (doi: 10.1007/s10086-014-1418-y)

[9] Humphrey, J.E. \& Bolton, A.J., The Hot Pressing of Dry-Formed Woodbased Composites, Part II. A Simulation Model for Heat and Moisture Transfer and Typical Results, Holzforchung, 43(3), pp. 199-206, 1989.

[10] Garcia, P.J., Avramidis, S. \& Lam, F., Internal Temperature and Pressure Responses to Flake Alignment during Hot-Pressing, Holz als Roh-und Werkstoff, 59, pp. 272-275, 2001. 